\title{
[6]-Gingerol Inhibits Chikungunya Virus Infection by Suppressing Viral Replication
}

\author{
Rahma F. Hayati $\mathbb{D D}^{1}$ Cynthia D. Better, ${ }^{2}$ Dionisius Denis ${ }^{1},{ }^{1}$ Amalina G. Komarudin, ${ }^{1}$ \\ Anom Bowolaksono $\left(1,{ }^{3}\right.$ Benediktus Yohan $(1),{ }^{1}$ and R. Tedjo Sasmono ${ }^{1}$ \\ ${ }^{1}$ Eijkman Institute for Molecular Biology, Ministry of Research and Technology/National Agency for Research and Innovation, \\ Jl. Diponegoro 69, Jakarta 10430, Indonesia \\ ${ }^{2}$ Faculty of Pharmacy, University of Strasbourg, 4 Rue Blaise Pascal, Strasbourg 67081, France \\ ${ }^{3}$ Cellular and Molecular Mechanisms in Biological System Research Group, Department of Biology, Faculty of Mathematics and \\ Natural Sciences, Universitas Indonesia, Depok, West Java, Indonesia
}

Correspondence should be addressed to R. Tedjo Sasmono; sasmono@eijkman.go.id

Received 7 December 2020; Revised 22 February 2021; Accepted 10 March 2021; Published 28 March 2021

Academic Editor: Yanjin Zhang

Copyright ( 2021 Rahma F. Hayati et al. This is an open access article distributed under the Creative Commons Attribution License, which permits unrestricted use, distribution, and reproduction in any medium, provided the original work is properly cited.

Chikungunya (CHIK) is a reemerging arboviral disease caused by chikungunya virus (CHIKV) infection. The disease is clinically hallmarked by prolonged debilitating joint pain. Currently, there is no specific antiviral medication nor commercial vaccine available for treatment of the disease, which makes the discovery or development of specific anti-CHIKV compounds a priority. Ginger (Zingiber officinale Roscoe) is widely known for its various health benefits. The compound [6]-gingerol is the main active ingredient found in ginger. This study sought to determine the potential of [6]-gingerol antiviral activity against CHIKV infection using in vitro human hepatocyte HepG2 cells. The antiviral activity mechanism was investigated using direct virucidal and four indirect (pre-, post-, full-, and prevention) treatment assays. [6]-Gingerol showed weak virucidal activity but significant indirect antiviral activity against CHIKV through post- and full treatment with $\mathrm{IC}_{50}$ of $0.038 \mathrm{mM}$ and $0.031 \mathrm{mM}$, respectively, without showing cell cytotoxicity. The results indicated that [6]-gingerol inhibits CHIKV infection through suppression of viral replication. Together, this study confirms the potential use of [6]-gingerol for CHIK antiviral compound.

\section{Introduction}

Chikungunya (CHIK) is an acute febrile illness caused by infection with chikungunya virus (CHIKV). Firstly isolated in Tanzania in 1952, CHIKV has spread mainly in tropical and subtropical regions where appropriate vectors are prevalent [1]. The reemergence of the virus in East Africa, India, and around the Indian ocean in 2004-2007 caused a massive outbreak with significant economic impacts [2]. In Indonesia, CHIKV was firstly reported in Sumatera in 1982 which then spread to other major islands [3,4]. Sporadic outbreaks have been reported in Java in 2000-2002, as well as recent detection of other provinces [4-6].

The virus, which belongs to the Alphavirus genus in the family of Togaviridae, is transmitted to humans by the bite of infected Aedes sp. mosquitoes. The CHIKV genome consists of $11.8 \mathrm{~kb}$ positive single-stranded RNA with two reading frames encoding four nonstructural proteins (NS1-NS4) in the first $5^{\prime}$ open reading frame and three structural (Capsid, $\mathrm{E} 1$, and $\mathrm{E} 2$ ) and two other proteins (E3 and $6 \mathrm{~K}$ ) in the second $3^{\prime}$ reading frame [7]. Phylogenetically, the virus has been classified into three distinct genotypes, namely, the West African, East Central, and South African (ECSA), and Asian genotypes [8].

The clinical symptoms of CHIK, which share great similarity with dengue, include fever, headache, rash, and myalgia with debilitating arthralgia as the hallmark of CHIKV infection [9]. Although CHIK has a lower fatality rate compared to similar arboviral disease such as dengue, the inconvenience caused by CHIKV infection greatly affects one's daily 
life as the crippling joint pain persists for quite a long period [10]. Currently, CHIK's treatments are only symptomatic with no specific antiviral medicine available. In addition, commercial vaccines are also unavailable in the market although several potential CHIKV vaccine candidates are now in the clinical stages of development [11]. Therefore, it is important to find an effective treatment to avoid the daily life-inconvenience caused by the disease, besides preventive measure such as controlling mosquito population.

Ginger (Zingiber officinale Roscoe), a plant whose rhizome is widely used in Asia as a spice and as a component in traditional herbal medicine, has been shown to have multiple health benefits [12]. A number of studies have demonstrated that the plant possesses biological activities such as antioxidant, antiinflammatory, antimicrobial, and anticancer effects [13-16]. In addition, ginger has also been reported to potentially prevent and manage obesity, diabetes mellitus, respiratory disorders, neurodegenerative diseases, and cardiovascular disease [17-21].

The compound [6]-gingerol is one of the major pharmacologically active constituents of ginger [12]. It is responsible for the pungent taste of fresh ginger caused by the presence of aromatic ketones in its chemical structure (Figure 1) [22]. This nonvolatile molecule possesses a favorable toxicity profile and various biological activities, such as antioxidation, anticancer, analgesic effect, and anti-inflammatory effects [23].

Here, we examine the antiviral activity of [6]-gingerol against CHIKV infection in vitro using HepG2 cells. We also sought to understand the mechanism of inhibition by comparing the different treatment assays. The findings may provide new insights on the use of [6]-gingerol in the management of CHIK disease.

\section{Material and Methods}

2.1. Cell Lines and Virus. All cells used were originally obtained from American Type Culture Collection (ATCC) and have been maintained in Eijkman Institute's cell repository. The human (Homo sapiens) hepatocyte HepG2 cell line and Syrian baby hamster's (Mesocricetus auratus) kidney BHK-21 cell line were maintained in RPMI medium supplemented with 10\% Fetal Bovine Serum (FBS), 1\% antibiotic/antimycotic, and $2 \mathrm{mM}$ of l-glutamine (all from Gibco-Thermo Fisher Scientific). The monkey kidney Vero (CCL81) cell line was maintained in MEM medium supplemented with 5\% of FBS, $1 \%$ antibiotic/antimycotic, and $2 \mathrm{mM}$ of l-glutamine (Gibco-Thermo Fisher Scientific). All cell lines were maintained at $37^{\circ} \mathrm{C}$ with $5 \% \mathrm{CO}_{2}$ supplementation.

CHIKV strain JMB-192 (designated as CHIKV-JMB192), isolated from a febrile patient in Jambi in 2015, has been characterized as an Asian genotype [6]. The virus was propagated in Vero-CCL81 and harvested when cytopathogenic effect (CPE) was observed in $70-80 \%$ of cells. Virus titer was measured by standard plaque assay on BHK-21 cells adapted from a DENV assay [24]. Briefly, $2 \times 10^{5}$ cells/well were seeded in 24-well plates followed by incubation at $37^{\circ} \mathrm{C}$ under $5 \% \mathrm{CO}_{2}$ for two days. Tenfold serial dilutions of CHIKV were added to the cells for 1 hour in $37^{\circ} \mathrm{C}$ and $5 \% \mathrm{CO}_{2}$. The inoculant was removed and replaced with overlay medium containing 1\% Aquacide II (Sigma-Aldrich)

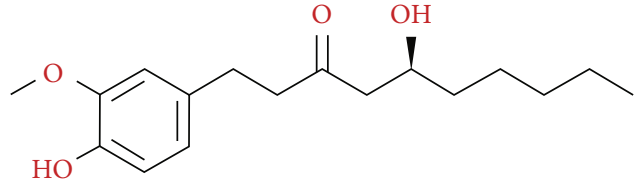

FIgURE 1: The chemical structure of 6-gingerol (source: http:// chemspider.com/Chemical-Structure.391126.html).

supplemented with $2 \%$ FBS, $1 \%$ antibiotic/antimycotic, and $2 \mathrm{mM}$ of l-glutamine (Gibco-Thermo Fisher Scientific) and incubated at $37^{\circ} \mathrm{C}$ under $5 \% \mathrm{CO}_{2}$ for three days. The cells were fixed with $3.7 \%$ formaldehyde (Sigma-Aldrich) and stained with $2 \%$ crystal violet (Sigma-Aldrich).

2.2. Active Compounds. The [6]-gingerol ((S)-5-hydroxy-1(4-hydroxy-3-methoxyphenyl)-3-decanone) (Sigma-Aldrich, GI046) was dissolved in 100\% dimethyl sulfoxide (DMSO) (Applichem CAS67-68-5) to a final concentration of $20 \mathrm{mM}$ and stored in $-20^{\circ} \mathrm{C}$ according to manufacturer's instruction. Ribavirin (Sigma-Aldrich, R9644) was used as a positive control at $2.6 \mu \mathrm{g} / \mathrm{ml}$ concentration, as demonstrated by Franco et al. [25]. The compound was dissolved in 100\% DMSO (Applichem CAS67-68-5), resulting in a stock concentration of $10 \mathrm{mg} / \mathrm{ml}$, and stored at $-20^{\circ} \mathrm{C}$ according to manufacturer's instruction. Both compounds were diluted to working concentration with complete RPMI medium. The highest final concentration of $0.75 \%$ DMSO in the working concentration (used in $0.15 \mathrm{mM}$ [6]-gingerol dilution) was included as a vehicle control.

2.3. Cell Cytotoxicity Assay. Cytotoxicity of [6]-gingerol to HepG2 was measured by a cell viability assay performed using the classical 3-(4,5-dimethyl-thiazol-2-yl)-2,5-diphenyltetrazolium bromide (MTT) (Vybrant-Thermo Fisher Scientific) assay. HepG2 were seeded $1 \times 10^{5}$ cells/well in 96-well plates and incubated overnight. The cells were challenged with medium, vehicle, or various concentrations of [6]-gingerol at $37^{\circ} \mathrm{C}$ and $5 \% \mathrm{CO}_{2}$. After 48 hours incubating, the medium was removed and replenished with $100 \mu \mathrm{l}$ fresh medium. The cell viability assay was then performed according to manufacturer's instruction. Briefly, $10 \mu \mathrm{l}$ of $12 \mathrm{mM}$ MTT stock was added to wells containing cells and then incubated at $37^{\circ} \mathrm{C}$ for 2 hours. After incubation, $100 \mu \mathrm{l}$ of the $10 \% \mathrm{SDS}$ in $0.01 \mathrm{M} \mathrm{HCl}$ solution was added, followed by overnight incubation at $37^{\circ} \mathrm{C}$. Absorbance from each well was measured at $570 \mathrm{~nm}$ using a microplate reader.

2.4. Virucidal Assay. We performed a virucidal assay to examine direct virucidal activity of [6]-gingerol against CHIKV, modified from Ahmad et al. [26]. Approximately 2 $\times 10^{5}$ PFU of CHIKV-JMB-192 was incubated directly with medium, vehicle, ribavirin, or various concentrations of [6]gingerol $(0.05 \mathrm{mM}, 0.1 \mathrm{mM}$, and $0.15 \mathrm{mM})$ at $37^{\circ} \mathrm{C}$ for 1 hour, after which infectious virus titer was determined by standard plaque assay. This was done in triplicate.

2.5. Antiviral Activity of [6]-Gingerol. Four different treatments were assayed to examine the indirect antiviral activity of [6]-gingerol: pre-, post-, full-, and prevention assay. 
Treatment was applied to $2 \times 10^{5}$ HepG2 cells/well seeded in 24-well plates, which had been incubated at $37^{\circ} \mathrm{C}$ and $5 \% \mathrm{CO}_{2}$ overnight. CHIKV-JMB-192 strain was used for infection with multiplicity of infection/MOI $=1.0$.

In pretreatment assay, CHIKV was pretreated with medium, vehicle, ribavirin, or various concentrations of [6]gingerol at $37^{\circ} \mathrm{C}$ for 1-hour preceding addition to HepG2 at $37^{\circ} \mathrm{C}$ and $5 \% \mathrm{CO}_{2}$ for 1 hour. The cells were washed and replenished with medium only following 48 hours of incubation at $37^{\circ} \mathrm{C}$ and $5 \% \mathrm{CO}_{2}$. In posttreatment, $\mathrm{CHIKV}$ was added to $\mathrm{HepG} 2$ cells for 1 hour at $37^{\circ} \mathrm{C}$ and $5 \% \mathrm{CO}_{2}$. After washing, the cells were treated with medium, vehicle, ribavirin, or various concentrations of [6]-gingerol and incubated at $37^{\circ} \mathrm{C}$ and $5 \% \mathrm{CO}_{2}$ for 48 hours. Full treatment was a combination of pre- and posttreatments. In the prevention assay, HepG2 cells were treated with medium, vehicle, ribavirin, or various concentrations of [6]-gingerol at $37^{\circ} \mathrm{C}$ and $5 \% \mathrm{CO}_{2}$ for 1 hour before being infected with $\mathrm{CHIKV}$ at $37^{\circ} \mathrm{C}$ and $5 \% \mathrm{CO}_{2}$ for 1 hour. After washing, the cells were supplemented with fresh medium and incubated at $37^{\circ} \mathrm{C}$ and $5 \% \mathrm{CO}_{2}$ for 48 hours. In all treatments, the supernatant was collected after 48 hours of incubation, as shown in Turnip et al. [27], and measured for viral titers by standard plaque assay.

2.6. Statistical Analysis. All statistical analysis was done using the SPSS Statistics program (Ver. 24), and the two-tailed $t$ -test for independent samples was used. A $p$ value of less than 0.05 was considered as statistically significant. The $50 \%$ cytotoxic concentration $\left(\mathrm{CC}_{50}\right)$ and $50 \%$ inhibitory concentration $\left(\mathrm{IC}_{50}\right)$ values were determined with AAT Bioquest QuestGraph $^{\mathrm{TM}} \mathrm{IC}_{50}$ calculator (https://www.aatbio.com/tools/ic50calculator). The selectivity index was calculated by dividing $\mathrm{CC}_{50}$ by $\mathrm{IC}_{50}$.

\section{Results}

3.1. Cytotoxicity of [6]-Gingerol. The MTT assay was used to determine the cytotoxicity of [6]-gingerol in HepG2 cells. The $50 \%$ cytotoxic concentration $\left(\mathrm{CC}_{50}\right)$ of [6]-gingerol was measured at $0.21 \mathrm{mM}$. No significant cytotoxicity was observed for cells treated with vehicle control (0.75\% DMSO) (Figure 2(a)), which was the highest final concentration of the solvent used to dissolve [6]-gingerol in cell culture media. Morphologic observation also showed that HepG2 cells treated with $\leq 0.2 \mathrm{mM}$ [6]-gingerol were healthy with minimal cell death. However, the cells treated with $>0.2 \mathrm{mM}[6]$-gingerol $(0.4 \mathrm{mM}, 0.5 \mathrm{mM}$, and $1.0 \mathrm{mM})$ gradually suffered cell death as the concentration increased (Figure 2(b)). The cell death was particularly significant at $1.0 \mathrm{mM}$ [6]-gingerol as almost all the cells were dead.

3.2. Evaluation of Virucidal Activity of [6]-Gingerol. To examine virucidal activity of [6]-gingerol, CHIKV was incubated at $37^{\circ} \mathrm{C}$ with medium only, vehicle, ribavirin, or various concentrations of [6]-gingerol for 1 hour. Upon incubation, virus viability and titer were determined by plaque assay. As presented in Figure 3, [6]-gingerol showed limited virucidal activity in a dose-dependent manner. At a low concentration $(0.05 \mathrm{mM})$, almost no virucidal activity of [6]-gin- gerol was observed. A reduction of viral titer was only observed at higher concentrations $(0.1 \mathrm{mM}$ and $0.15 \mathrm{mM})$ with less than $1 \log _{10}$ (or around 30\%) viral reduction at the highest concentration tested. The measured $\mathrm{IC}_{50}$ was $0.24 \mathrm{mM}$ for virucidal activity in comparison to untreated medium control. Ribavirin also showed relatively weak virucidal activity with approximately $20 \%$ reduction of viral titer.

3.3. [6]-Gingerol Inhibits CHIKV Replication in Post- and Full-Treatment Assays. To identify the indirect antiviral activity of [6]-gingerol and its mechanism, we employed four different assays: pre-, post-, full-, and prevention assays. Antiviral activity was observed in post- and full-treatment assay, even at the lowest concentration tested (Figure 4). At $0.05 \mathrm{mM}$, [6]-gingerol significantly reduced approximately $75 \%$ of viral titer. At higher concentrations $(0.1 \mathrm{mM}$ and $0.15 \mathrm{mM}$ ), more than $95 \%$ viral reduction was achieved. The findings indicate that [6]-gingerol effectively inhibits $\mathrm{CHIKV}$ infection by suppressing viral replication. The measured $\mathrm{IC}_{50}$ for both assays were $0.038 \mathrm{mM}$ and $0.031 \mathrm{mM}$ for post- and full-treatment assay, respectively, which were much lower than the observed $\mathrm{CC}_{50}$. The selectivity index indicates a value around 5 and 8 for the post- and full treatment, respectively.

\section{Discussion}

Although CHIK has a lower fatality rate compared to similar arboviral disease such as dengue, the daily life of an infected person is greatly affected as the joint pain remains for quite a long period. Therefore, the development of CHIKV antiviral agents needs to target a significant reduction of viral load in order to prevent the debilitating effects caused by the immune response. Secondary metabolites may serve as prospective antiviral agents since many of them have been proven to effectively treat the disease with additional benefits. Ginger has been used as a herbal remedy for generations, especially in Asian countries. Due to its widely known various health benefits, we examined the antiviral activity of [6]-gingerol, one of the main bioactive compounds of ginger against CHIKV. We used the wild-type CHIKV circulating in Indonesia as challenge virus which has been characterized as Asian genotype [6]. Currently, this genotype is the predominant CHIKV genotype in Indonesia, making up more than ninety percent of cases [4].

In this study, we used the HepG2 cell line for cytotoxicity, virucidal, and antiviral assays. For in vitro study, HepG2 has been proven to have a high susceptibility to CHIKV infection [28]. Therefore, this cell line has been used in CHIKV antiviral studies $[29,30]$. With regard to CHIK pathogenesis in humans, CHIKV was also reported to disseminate to the liver after replication in the skin [7]. Hence, using the HepG2 cell line may help mimic the CHIKV pathogenesis in humans.

We examined the cytotoxicity of [6]-gingerol in the HepG2 cell line. The $\mathrm{CC}_{50}$ of [6]-gingerol in HepG2 after a $48 \mathrm{hr}$ incubation was $0.21 \mathrm{mM}$. Morphologically, the cells challenged with [6]-gingerol at concentrations less than the $\mathrm{CC}_{50}$ were healthy with minimal cell death, confirming the $\mathrm{CC}_{50}$ concentration. The same cytotoxicity study using different cell lines showed 


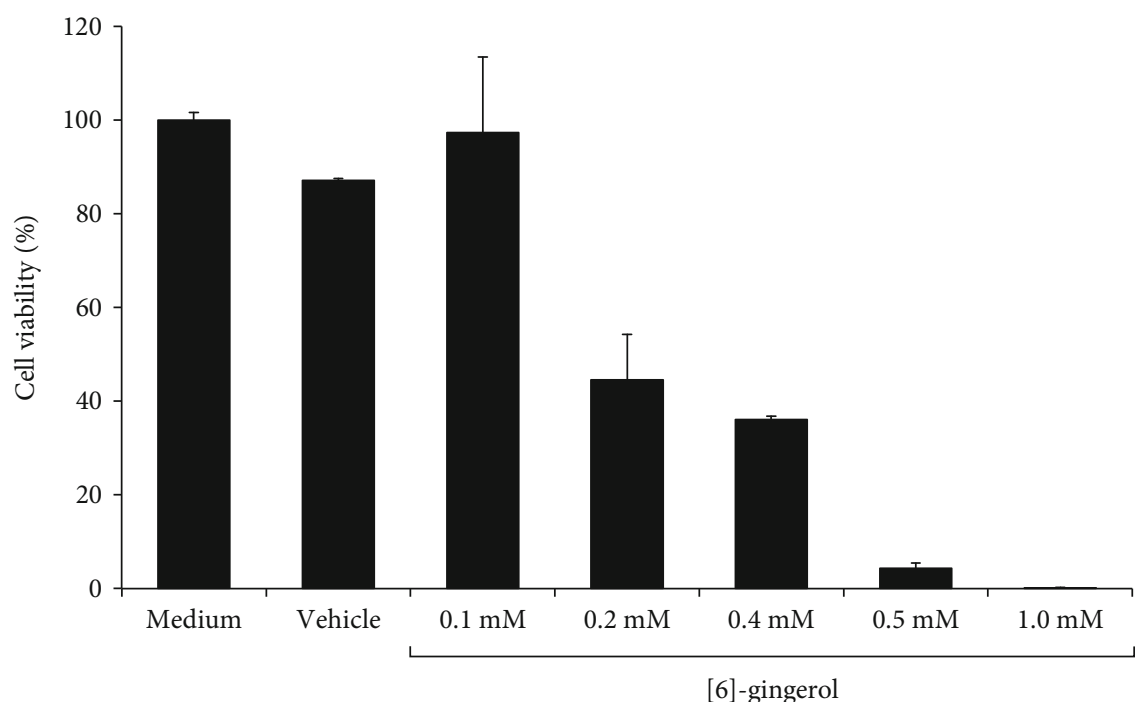

(a)
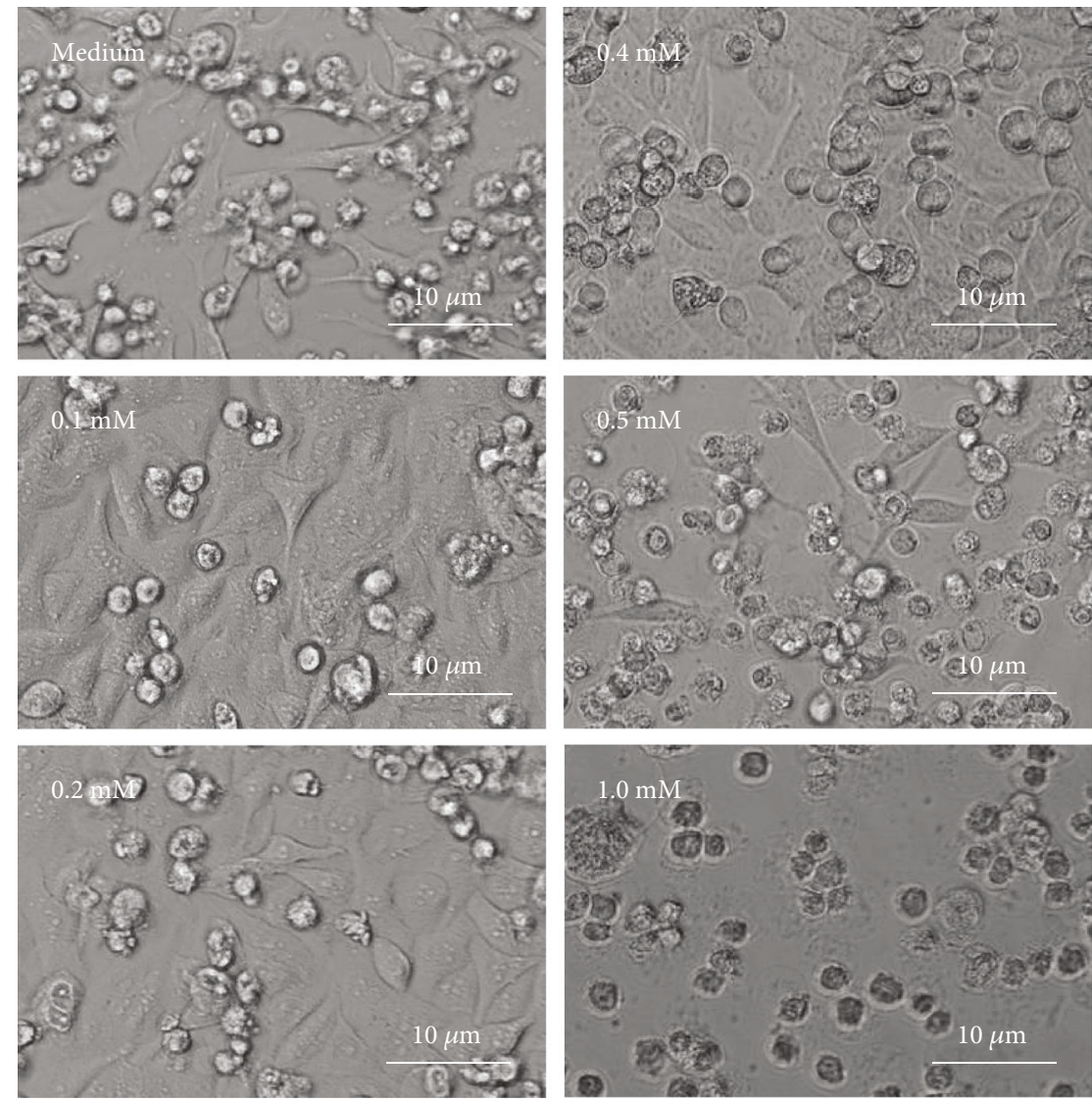

(b)

FIGURE 2: Determination of [6]-gingerol cytotoxicity in HepG2 cells by MTT assay. (a) HepG2 cells were incubated with medium, vehicle, or [6]-gingerol ( $0.1 \mathrm{mM}, 0.2 \mathrm{mM}, 0.4 \mathrm{mM}, 0.5 \mathrm{mM}$, and $1.0 \mathrm{mM})$ for 48 hours followed by MTT cell viability assay. Data derived from triplicates. (b) Morphology of HepG2 cells after 48 hours of incubation with medium or [6]-gingerol.

half of our $\mathrm{CC}_{50}$ value $(0.1 \mathrm{mM}, 0.102 \mathrm{mM}$, and $0.102 \mathrm{mM}$ for HCT15, L929, and RAW264.7, respectively) when treated for 24 hours [31]. This might be caused by the shorter incubation period and the different cell lines used. In our study, we treated the cells for 48 hours since the CHIKV infection in HepG2 cells was maximized after 48 hours of incubation, as shown in our previous study [27].

We examined the direct virucidal activity of [6]-gingerol against CHIKV. As presented in Figure 3, [6]-gingerol showed limited virucidal activity. Inhibition of viral activity 


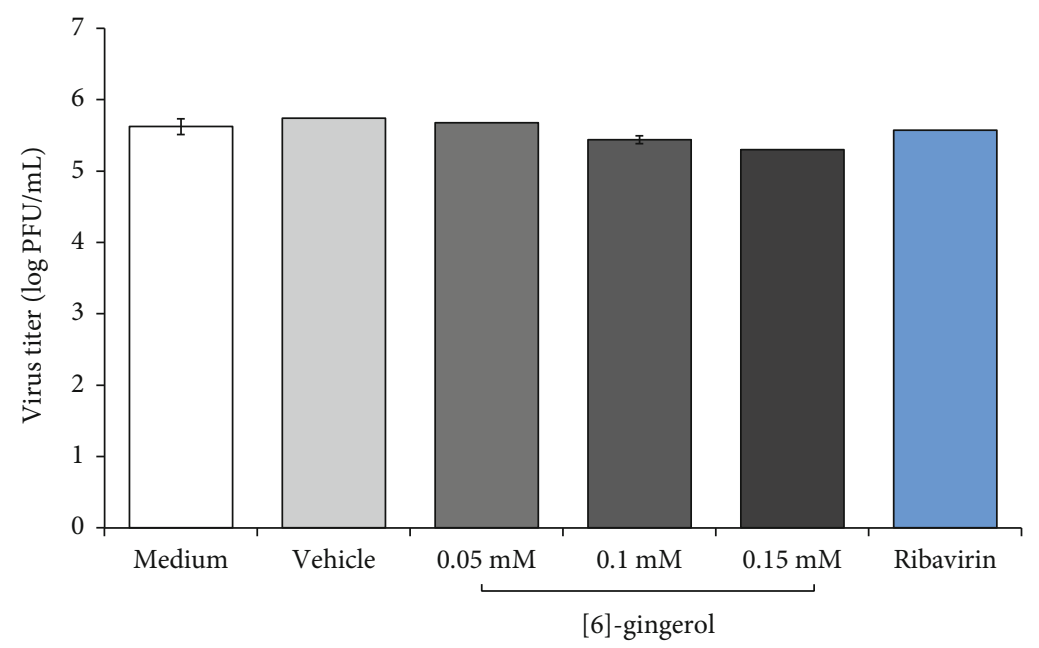

Figure 3: Evaluation of virucidal activity of [6]-gingerol against CHIKV. CHIKV-JMB-192 was incubated directly with medium, vehicle, ribavirin, or [6]-gingerol $(0.05 \mathrm{mM}, 0.1 \mathrm{mM}$, and $0.15 \mathrm{mM})$ at $37^{\circ} \mathrm{C}$ and $5 \% \mathrm{CO}_{2}$ for 1 hour. Virus titer was determined by standard plaque assay. Data derived from triplicates.

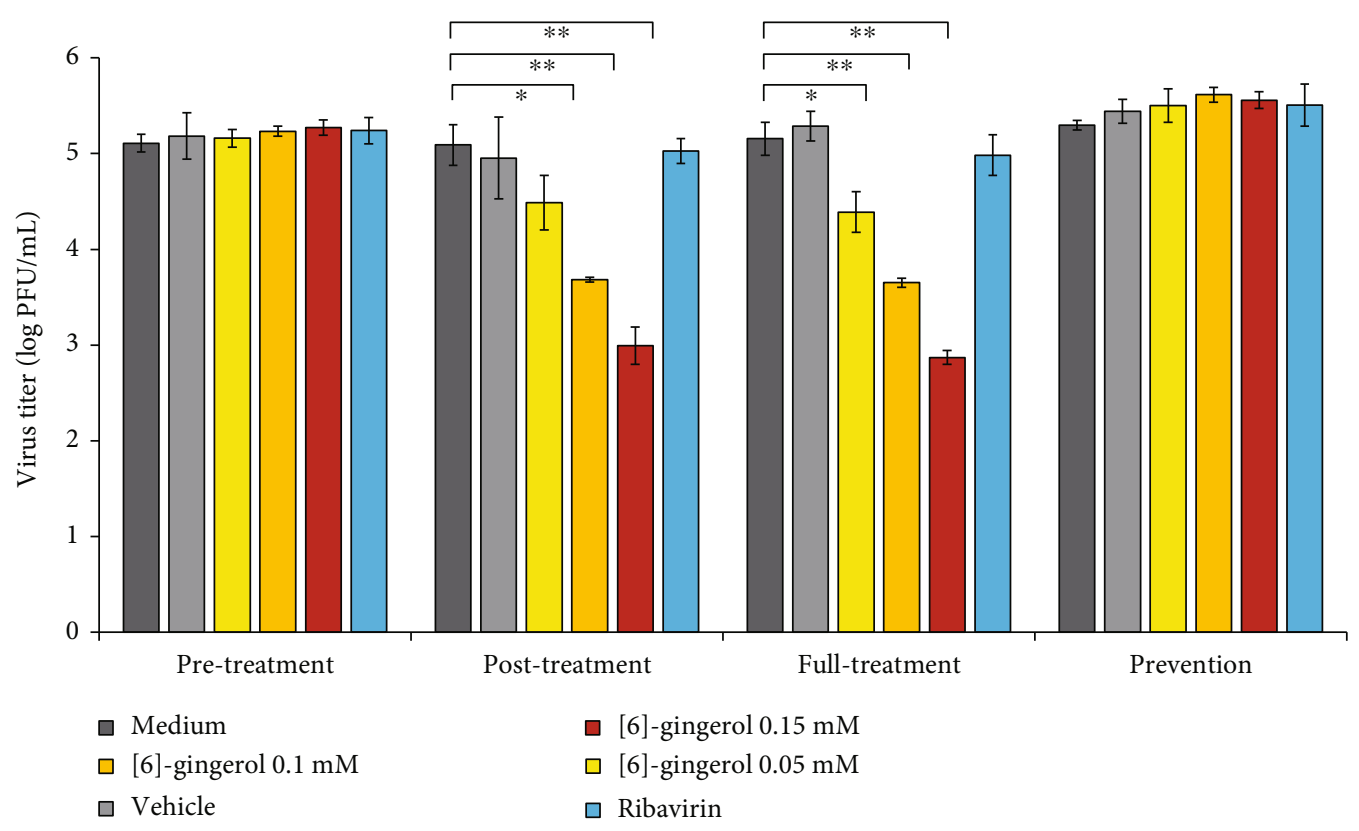

FIGURE 4: Evaluation of antiviral activity of [6]-gingerol upon CHIKV infection in HepG2 cells. Antiviral activity of [6]-gingerol was evaluated in pre-, post-, full-, and prevention treatment cell modes. Viral titer was measured by standard plaque assay. Statistical significance was determined using two-tailed $t$-test for independent samples $\left({ }^{*} p<0.01\right.$ and $\left.{ }^{* *} p<0.001\right)$.

was only observed at higher concentrations $(0.1 \mathrm{mM}$ and $0.15 \mathrm{mM}$ ) with less than $1 \log _{10} \mathrm{PFU} / \mathrm{mL}$ viral reduction. Virucidal compounds inhibit viral activity by inactivating extracellular viral particles or by penetrating virions and destroying the viral genome [26]. As a control, ribavirin showed virucidal activity, although relatively little, which was also observed elsewhere [32, 33].

As [6]-gingerol only showed relatively limited direct virucidal activity against CHIKV, we examined the indirect antiviral activity of the compound in HepG2 cells. We employed four indirect antiviral assays. The pretreatment assay was designed to identify the ability of [6]-gingerol to block virus entry to host cells during infection while the post- treatment assay examined the ability of [6]-gingerol to inhibit viral replication within $\mathrm{CHIKV}$-infected cells. The full-treatment assay, a combination of pre- and posttreatment assays, examined the full antiviral capacity of [6]-gingerol against CHIKV. The prevention assay monitored protective effect of [6]-gingerol treatment to the host cells preceded CHIKV infection.

From the four assays employed, antiviral activity was observed in the post- and full-treatment assays, indicating that [6]-gingerol effectively inhibits viral replication after CHIKV infects the cells. The $\mathrm{IC}_{50}$ were $0.038 \mathrm{mM}$ and $0.031 \mathrm{mM}$ for post- and full-treatment assays, respectively, which were much lower than the $\mathrm{CC}_{50}$. The selectivity index 
(SI) is an important indicator to identify the promising antiviral activity of a compound with negligible toxicity. Theoretically, a higher SI indicates the effectiveness and safety of the compound. Here, we found the selectivity index of [6]gingerol was 5 and 8 for the post- and full treatments, respectively. Although these SIs were not very high, they indicate that [6]-gingerol has the potential to treat CHIKV infection. For comparison, the reduction of viral load by [6]-gingerol was significantly higher than ribavirin.

Several studies have reported on the antiviral activity of fresh ginger, ginger extract, or other processed forms of ginger through various modes of action. Ginger essential oil was reported to have direct antiviral activity against herpes simplex virus type 2 [34]. Influenza virus H9N2 replication was inhibited by aqueous extract of ginger in vitro [35]. Fresh ginger was reported to inhibit human respiratory syncytial virus activity by blocking viral attachment and internalization [36]. Together, these findings indicate that the compound behaves differently depending on the pathogen.

Understanding the mechanism of action of antiviral compounds is an important step in drug development which helps their evaluation and application in disease treatment. In this study, we observed that the antiviral mechanism of [6]-gingerol was the inhibitory effect on CHIKV replication after the virus infects host cells. Similar antiviral mechanisms have been reported. Harringtonine, a cephalotaxine alkaloid, inhibited CHIKV replication in the early stages which occurred after viral entry into cells [37]. Several flavonoids were also reported to inhibit CHIKV replication at postentry stage, including silymarin, hesperitin, and naringenin [38, 39]. However, different antiviral mechanisms were also observed with different compounds. For example, curcumin inhibited binding of viruses to the cells during CHIKV infection [40]. Therefore, the antiviral mechanism seems to be very specific for each compound. Regarding its weak virucidal activity, inhibition of CHIKV replication at posttreatment by [6]-gingerol indicates an important role in host defensive mechanisms. Practically, inhibition of viral replication is more applicable for CHIK treatment since it allows the antiviral drug to be administered after someone is infected with CHIKV rather than as a supplement that is consumed before infection occurs.

\section{Conclusion}

This study was the first to report the antiviral activity of [6]gingerol against CHIKV and its possible mechanism of action. Considering the substantial public and economic impact of CHIKV infection due to the prolonged persisting arthralgia, this study provides insight into the potential use of [6]-gingerol as an antiviral agent for CHIKV infection. Further studies are encouraged to establish effective strategies to utilize [6]-gingerol for CHIK treatment.

\section{Data Availability}

The antiviral data used to support the findings of this study are included within the article.

\section{Conflicts of Interest}

The authors declare that there are no conflicts of interest in this study.

\section{Authors' Contributions}

Rahma F. Hayati and Cynthia D. Better are authors with equal contributions.

\section{Acknowledgments}

This work was supported by the APBN grant Ministry of Research and Technology of the Republic of Indonesia and Kemenristekdikti Basic Science Grant No. 8/E1/KP.PTNBH/2020. We would like to thank Justus Sievers for proofreading the manuscript.

\section{References}

[1] M. C. Robinson, "An epidemic of virus disease in Southern Province, Tanganyika Territory, in 1952-53. I. Clinical features," Transactions of the Royal Society of Tropical Medicine and Hygiene, vol. 49, no. 1, pp. 28-32, 1955.

[2] G. Pialoux, B.-A. Gaüzère, S. Jauréguiberry, and M. Strobel, "Chikungunya, an epidemic arbovirosis," The Lancet Infectious Diseases, vol. 7, no. 5, pp. 319-327, 2007.

[3] K. Laras, N. C. Sukri, R. P. Larasati et al., "Tracking the reemergence of epidemic chikungunya virus in Indonesia," Transactions of the Royal Society of Tropical Medicine and Hygiene, vol. 99, no. 2, pp. 128-141, 2005.

[4] H. Harapan, A. Michie, M. Mudatsir et al., "Chikungunya virus infection in Indonesia: a systematic review and evolutionary analysis," BMC Infectious Diseases, vol. 19, no. 1, p. 243, 2019.

[5] K. Sari, K. S. A. Myint, A. R. Andayani et al., "Chikungunya fever outbreak identified in North Bali, Indonesia," Transactions of the Royal Society of Tropical Medicine and Hygiene, vol. 111, no. 7, pp. 325-327, 2017.

[6] R. T. Sasmono, A. Perkasa, B. Yohan et al., "Chikungunya detection during dengue outbreak in Sumatra, Indonesia: clinical manifestations and virological profile," The American Journal of Tropical Medicine and Hygiene, vol. 97, no. 5, pp. 1393-1398, 2017.

[7] O. Schwartz and M. L. Albert, "Biology and pathogenesis of chikungunya virus," Nature Reviews. Microbiology, vol. 8, no. 7, pp. 491-500, 2010.

[8] L. C. Ng and H. C. Hapuarachchi, "Tracing the path of chikungunya virus-evolution and adaptation," Infection, Genetics and Evolution, vol. 10, no. 7, pp. 876-885, 2010.

[9] S.-D. Thiberville, N. Moyen, L. Dupuis-Maguiraga et al., "Chikungunya fever: epidemiology, clinical syndrome, pathogenesis and therapy," Antiviral Research, vol. 99, no. 3, pp. $345-$ 370, 2013.

[10] L. Dupuis-Maguiraga, M. Noret, S. Brun, R. le Grand, G. Gras, and P. Roques, "Chikungunya disease: infection-associated markers from the acute to the chronic phase of arbovirusinduced arthralgia," PLoS Neglected Tropical Diseases, vol. 6, no. 3, p. e1446, 2012.

[11] W. Akahata, Z.-Y. Yang, H. Andersen et al., "A virus-like particle vaccine for epidemic chikungunya virus protects 
nonhuman primates against infection," Nature Medicine, vol. 16, no. 3, pp. 334-338, 2010.

[12] Q.-Q. Mao, X.-Y. Xu, S.-Y. Cao et al., "Bioactive compounds and bioactivities of ginger (Zingiber officinale Roscoe)," Food, vol. 8, no. 6, p. 185, 2019.

[13] J. Citronberg, R. Bostick, T. Ahearn et al., "Effects of ginger supplementation on cell-cycle biomarkers in the normalappearing colonic mucosa of patients at increased risk for colorectal cancer: results from a pilot, randomized, and controlled trial," Cancer Prevention Research (Philadelphia, Pa.), vol. 6, no. 4, pp. 271-281, 2013.

[14] S. H. Nile and S. W. Park, "Chromatographic analysis, antioxidant, anti-inflammatory, and xanthine oxidase inhibitory activities of ginger extracts and its reference compounds," Industrial Crops and Products, vol. 70, pp. 238-244, 2015.

[15] N. Vijendra Kumar, P. S. Murthy, J. R. Manjunatha, and B. K. Bettadaiah, "Synthesis and quorum sensing inhibitory activity of key phenolic compounds of ginger and their derivatives," Food Chemistry, vol. 159, pp. 451-457, 2014.

[16] M. Zhang, E. Viennois, M. Prasad et al., "Edible ginger-derived nanoparticles: a novel therapeutic approach for the prevention and treatment of inflammatory bowel disease and colitisassociated cancer," Biomaterials, vol. 101, pp. 321-340, 2016.

[17] A. J. Akinyemi, G. R. Thome, V. M. Morsch et al., "Effect of dietary supplementation of ginger and turmeric rhizomes on angiotensin-1 converting enzyme (ACE) and arginase activities in L-NAME induced hypertensive rats," Journal of Functional Foods, vol. 17, pp. 792-801, 2015.

[18] S.-C. Ho, K.-S. Chang, and C.-C. Lin, "Anti-neuroinflammatory capacity of fresh ginger is attributed mainly to 10-gingerol," Food Chemistry, vol. 141, no. 3, pp. 3183-3191, 2013.

[19] S. Suk, G. T. Kwon, E. Lee et al., "Gingerenone A, a polyphenol present in ginger, suppresses obesity and adipose tissue inflammation in high-fat diet-fed mice," Molecular Nutrition \& Food Research, vol. 61, no. 10, p. 1700139, 2017.

[20] J. Walstab, D. Krüger, T. Stark et al., "Ginger and its pungent constituents non-competitively inhibit activation of human recombinant and native 5-HT3 receptors of enteric neurons," Neurogastroenterology \& Motility, vol. 25, no. 5, p. 439-e302, 2013.

[21] C.-K. Wei, Y.-H. Tsai, M. Korinek et al., "6-Paradol and 6-shogaol, the pungent compounds of ginger, promote glucose utilization in adipocytes and myotubes, and 6-paradol reduces blood glucose in high-fat diet-fed mice," International Journal of Molecular Sciences, vol. 18, no. 1, p. 168, 2017.

[22] R. B. Semwal, D. K. Semwal, S. Combrinck, and A. M. Viljoen, "Gingerols and shogaols: important nutraceutical principles from ginger," Phytochemistry, vol. 117, pp. 554-568, 2015.

[23] S. M. Zick, Z. Djuric, M. T. Ruffin et al., "Pharmacokinetics of 6-gingerol, 8-gingerol, 10-gingerol, and 6-shogaol and conjugate metabolites in healthy human subjects," Cancer Epidemiology, Biomarkers \& Prevention, vol. 17, no. 8, pp. 1930-1936, 2008.

[24] J. Fink, F. Gu, L. Ling et al., "Host gene expression profiling of dengue virus infection in cell lines and patients," PLoS Neglected Tropical Diseases, vol. 1, no. 2, p. e86, 2007.

[25] E. J. Franco, J. L. Rodriquez, J. J. Pomeroy, K. C. Hanrahan, and A. N. Brown, "The effectiveness of antiviral agents with broad-spectrum activity against chikungunya virus varies between host cell lines," Antiviral Chemistry \& Chemotherapy, vol. 26, p. 204020661880758, 2018.
[26] S. A. Abdul Ahmad, U. D. Palanisamy, B. A. Tejo, M. F. Chew, H. W. Tham, and S. Syed Hassan, "Geraniin extracted from the rind of Nephelium lappaceum binds to dengue virus type-2 envelope protein and inhibits early stage of virus replication," Virology Journal, vol. 14, no. 1, p. 229, 2017.

[27] O. N. Turnip, R. F. Hayati, R. Alawiyah et al., "Growth characteristics of chikungunya virus isolate from Indonesia in various human cell lines in vitro," Microbiology Indonesia, vol. 13, no. 1, pp. 1-8, 2019.

[28] M. Sourisseau, C. Schilte, N. Casartelli et al., "Characterization of reemerging chikungunya virus," PLoS Pathogens, vol. 3, no. 6, article e89, 2007.

[29] N. Wikan, P. Sakoonwatanyoo, S. Ubol, S. Yoksan, and D. R. Smith, "Chikungunya virus infection of cell lines: analysis of the East, Central and South African lineage," PLoS One, vol. 7, no. 1, p. e31102, 2012.

[30] P. Wintachai, P. Kaur, R. C. H. Lee et al., "Activity of andrographolide against chikungunya virus infection," Scientific Reports, vol. 5, no. 1, p. 14179, 2015.

[31] K. M, S. MR, N. PA, and B. T, "6-Gingerol is the most potent anticancerous compound in ginger (Zingiber officinale Rosc.)," Journal of Developing Drugs, vol. 6, no. 1, 2017.

[32] C. C. Cirne-Santos, C. S. Barros, C. C. R. Nogueira et al., "Inhibition by marine algae of chikungunya virus isolated from patients in a recent disease outbreak in Rio de Janeiro," Frontiers in Microbiology, vol. 10, p. 2426, 2019.

[33] C. C. Cirne-Santos, C. de Souza Barros, M. C. de Oliveira et al., "_In vitro_Studies on The Inhibition of Replication of Zika and Chikungunya Viruses by Dolastane Isolated from Seaweed _Canistrocarpus cervicornis_,'Scientific Reports, vol. 10, no. 1, p. $8263,2020$.

[34] C. Koch, J. Reichling, J. Schneele, and P. Schnitzler, "Inhibitory effect of essential oils against herpes simplex virus type 2," Phytomedicine, vol. 15, no. 1-2, pp. 71-78, 2008.

[35] A. Rasool, M.-U.-R. Khan, M. A. Ali et al., "Anti-avian influenza virus H9N2 activity of aqueous extracts of Zingiber officinalis (ginger) and Allium sativum (garlic) in chick embryos," Pakistan Journal of Pharmaceutical Sciences, vol. 30, no. 4, pp. 1341-1344, 2017.

[36] J. S. Chang, K. C. Wang, C. F. Yeh, D. E. Shieh, and L. C. Chiang, "Fresh ginger (Zingiber officinale) has anti-viral activity against human respiratory syncytial virus in human respiratory tract cell lines," Journal of Ethnopharmacology, vol. 145, no. 1, pp. 146-151, 2013.

[37] P. Kaur, M. Thiruchelvan, R. C. H. Lee et al., "Inhibition of chikungunya virus replication by harringtonine, a novel antiviral that suppresses viral protein expression," Antimicrobial Agents and Chemotherapy, vol. 57, no. 1, pp. 155-167, 2012.

[38] R. Lani, P. Hassandarvish, C. W. Chiam et al., "Antiviral activity of silymarin against chikungunya virus," Scientific Reports, vol. 5, no. 1, 2015.

[39] A. Ahmadi, P. Hassandarvish, R. Lani et al., "Inhibition of chikungunya virus replication by hesperetin and naringenin," RSC Advances, vol. 6, no. 73, pp. 69421-69430, 2016.

[40] B. C. Mounce, T. Cesaro, L. Carrau, T. Vallet, and M. Vignuzzi, "Curcumin inhibits Zika and chikungunya virus infection by inhibiting cell binding," Antiviral Research, vol. 142, pp. 148$157,2017$. 